\title{
SCIDiC
}

\author{
International Journal of Dentistry and Oral Science (IJDOS) \\ ISSN: 2377-8075
}

\section{Awareness and Practice Of Wearing Protective Eye Wear Among Dental Students}

Research Article

Satya Prakash ${ }^{1}$, Dhanraj Ganapathy²

${ }^{1}$ Post Graduate, Department of Prosthodontics, Saveetha Dental College and Hospitals, Saveetha University, Chennai, India.

${ }^{2}$ Professor \& Head of Department, Department of Prosthodontics, Saveetha Dental College and Hospitals, Saveetha University, Chennai, India.

\section{Abstract}

Introduction: Unique protective eyewear such as goggles, face masks including safety glasses is extremely effective while worn and correctly designed to avoid the impact on the eyes of foreign materials, pollutants, hot objects, infectious agents, radiation and they potentially minimize the extent of an impact.

Aim: The study aimed to assess the knowledge and practice among dental students about wearing safety eye protection devices.

Materials and Method: A cross-sectional analysis with a self-designed questionnaire was performed, with Ten questions distributed amongst 100 dental students. The questionnaire examined information in dental applications about wearing protective eye wear, their protective effects against high-speed missiles, protective effects against high-speed aerosols, and explanations for not wearing eye wear. We reported and evaluated the responses.

Results: $15 \%$ of the respondents were aware of wearing protective eye wear in dental applications. $14 \%$ wore protective eye wear in dental applications $13 \%$ were aware of the protective effects of eye wear against high speed projectiles in dental applications, $11 \%$ were aware of protective effects of eye wear against high speed aerosols in dental applications and $11 \%$ said wearing eye wear affected comfort, $13 \%$ said it affected clarity of vision and $76 \%$ said fogging of vision as the main reasons for not wearing protective eye wear.

Conclusion: There is limited awareness amongst dental students over the use of protective eye wear in dental applications. The study findings indicate that there are many potentially modifiable factors that could contribute to increased use of protective eye wear among students, and indicate that teachers need to provide ongoing positive input that promotes the continued use of PPE among dental students.

Keywords: Awareness; Eeyewear; Injury.

\section{Introduction}

Acute eye damage is a frequent occurrence at workplace and at home globally [1, 2], but many cases of occurrence are completely avoidable with effective need for protective eyewear [3]. A research by the Bureau of Labor Statistics (BLS) found that 60 per cent of those with work-related eye injury either did not wear protective eyewear or wear different kind at the time of injury (Bureau of Labor Statistics, 1999).
Relative to other work-related accidents, the risk of work-related ocular accidents is comparatively high. Ocular injuries are estimated to represent between $5.0 \%$ [2] and $6.1 \%$ of all claims for compensation for employees. In one population study, 57.1 percent of the 10,620 serious eye injuries reported inside an ophthalmic emergency facility [1] happened at workplace. Ocular injuries differ in intensity; nevertheless, they can lead to permanent loss of sight and/or function and 16 percent of all work-related eye damage are reported to be serious [4].

\section{*Corresponding Author:}

DhanrajGanapathy,

Professor \& Head of Department, Department of Prosthodontics, Saveetha Dental College and Hospitals, Saveetha University, Chennai, India. Tel: 9841504523

Email Id: dhanrajmganapathy@yahoo.co.in

Received: February 25, 2021

Accepted: March 04, 2021

Published: March 18, 2021

Citation: Satya Prakash, Dhanraj Ganapathy. Awareness and Practice Of Wearing Protective Eye Wear Among Dental Students. Int J Dentistry Oral Sci. 2021;08(03):2084-2086. doi: http://dx.doi.org/10.19070/2377-8075-21000410

Copyright: Dhanraj Ganapathy ${ }^{\circ} 2021$. This is an open-access article distributed under the terms of the Creative Commons Attribution License, which permits unrestricted use, distribution and reproduction in any medium, provided the original author and source are credited. 
Specific protective eyewear like goggles, face masks and protective goggles is highly effective when worn and appropriately designed to prevent the effect of external products, toxins, hot substances, infectious agents, radiation on the eyes and potentially reduce the severity of an injury $[4,5]$. A study of the efficacy of measures to avoid work-related eye injuries showed that when EPP is used, both the risk of eye injury or loss of work time can indeed be decreased by $50 \%$ or more.

Across different occupations multiple aspects associated with the use of protective eyewear were reported, for example across farm workers researchers reported discomfort, fogging and certain visibility problems and perceived lack of security, while other studies reported similar results, in response to factors such as community 'norms, space and scarcity of reinforcement or compliance $[6,7]$. Dentistry is a occupation with a significant risk of eye injury due to the multiple clinical and restorative procedures used in the care of patients, and use of appropriate eye protection is important to avoid injury. The study aimed to assess the knowledge and practice among dental students about wearing safety eye protection devices.

\section{Materials and Method}

A cross-sectional analysis with a self-designed questionnaire was performed, with Ten questions distributed amongst 100 dental students. The questionnaire examined information in dental applications about wearing protective eye wear, their protective effects against high-speed missiles, protective effects against highspeed aerosols, and explanations for not wearing eye wear. We reported and evaluated the responses.

\section{Results}

$15 \%$ of the respondents were aware of wearing protective eye wear in dental applications (Fig 1). 14\% wore protective eye wear in dental applications (Fig 2). 13\% were aware of the protective effects of eye wear against high speed projectiles in dental applications (Fig 3), 11\% were aware of protective effects of eye wear against high speed aerosols in dental applications (Fig 4) and 11\% said wearing eye wear affected comfort, $13 \%$ said it affected clarity of vision and $76 \%$ said fogging of vision as the main reasons for not wearing protective eye wear (Fig 5).

Figure 1. Awarenes of wearing protective eye wear in dental applications.

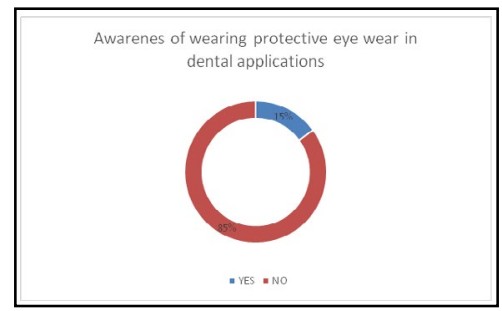

Figure 2. Practice of wearing protective eye wear in dental applications.

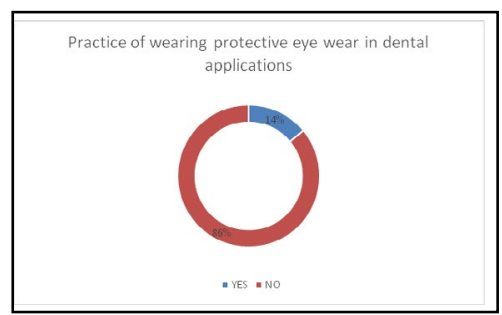

Figure 3. Awarenes of the protective effects of eye wear against high speed projectiles in dental applications.

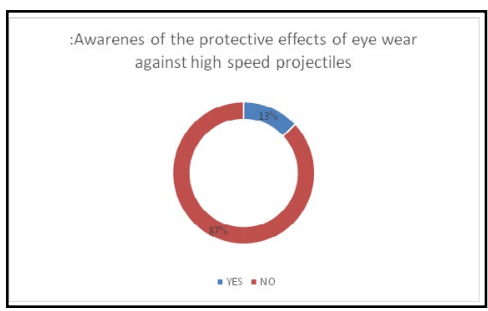

Figure 4. Awareness of the protective effects of eye wear against high speed aerosols in dental applications.

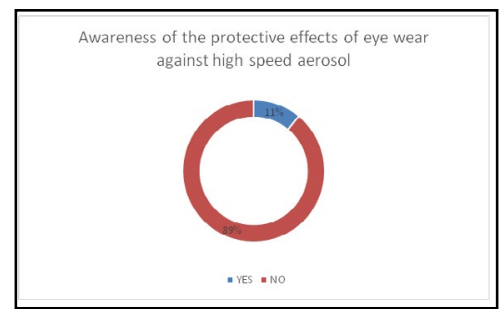


Figure 5. Reasons for not wearing protective eye wear.

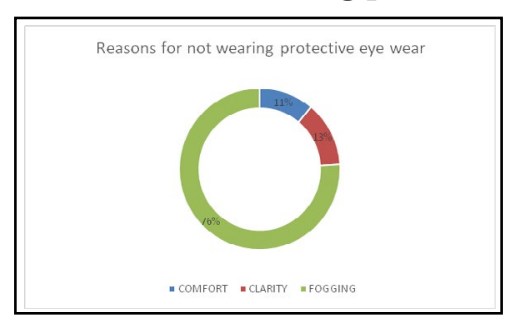

\section{Discussion}

When properly worn, the protective eyewear is considered to be highly effective both in preventing the impact of hazards on the eye and in minimizing the seriousness of an injury when an impact occurs [7]. Traumatic eye injury, however, remains an important concern for workplace health and safety.

The younger novice operators were typically less likely to consider the possibility of eye injury and less prone to be using PPE. This is aligned with Forrest et al [8]. 's research that showed just 15.3 per cent of those 18-24 years and older using eye protection when engaged in behaviors outside the workplace that may result in eye injury. Programs that target young operators can be successful in increasing their risk perception. The other two variables that have been identified impacting risk perception were safety training and work climate. After initial safety training the participants indicated the need for refresher courses. This recommendation is in line with the need for targeting young operators.

With regard to many other significant aspects linked to use of PPE, while suppliers continue to develop the design and functionality of safety eye wear, based on the findings of this report, it is evident either that several people may not have access to some of the more recent designs or are ignorant of their availability, and it was also the observation of Forst et al. [5] and Lipscomb [6]. Comfort, visibility, and fogging remain problems for so many of the operators, usually due to work climate and operator experiences.

Protective eyewear often needs to accommodate either prescription glasses or the lenses themselves would have to be prescription; however, many of the participants had to provide their own eyewear and made suggestions as to how this affected their actions in terms of usage. However, even when the PPE was made available to the operator, easy access to it was important. Some good suggestions included providing carrying cases, straps or necklaces to keep them handy at all times.

Clear communication from establishments [9] and a stricter security policy could increase the use of PPE. Another potentially effective strategy to help address this problem is operational approaches and procedures, such as enlisting a team of workers to aid in the procurement and assessment of PPE, together with supervisors. Modern methods to participative ergonomics have shown that judgment on resources, equipment and working environment design will achieve greater approval of the security strategy and practice and participation in the solution, from all participants, including the operators [10]. Focus groups are really an proven qualitative tool for understanding safety-related behavioral awareness, attitude, and beliefs [11, 12]. A similar approach should be encouraged with teachers advising the students positively and consistently on the use of protective eye wear to avoid ocular damage to students throughout dental applications.

\section{Conclusion}

There is limited awareness amongst dental students over the use of protective eye wear in dental applications. The study findings indicate that there are many potentially modifiable factors that could contribute to increased use of protective eyewear among students, and indicate that teachers need to provide ongoing positive input that promotes the continued use of PPE among dental students.

\section{References}

[1]. Fea A, Bosone A, Rolle T, Grignolo FM. Eye injuries in an Italian urban population: report of 10,620 cases admitted to an eye emergency department in Torino. Graefes Arch ClinExpOphthalmol. 2008 Feb;246(2):175-9. Pubmed PMID: 18183412.

[2]. Lombardi DA, Pannala R, Sorock GS, Wellman H, Courtney TK, Verma S, et al. Welding related occupational eye injuries: a narrative analysis. Inj Prev. 2005 Jun;11(3):174-9. Pubmed PMID: 15933411.

[3]. Mancini G, Baldasseroni A, Laffi G, Curti S, Mattioli S, Violante FS. Prevention of work related eye injuries: long term assessment of the effectiveness of a multicomponent intervention among metal workers. Occup Environ Med. 2005 Dec;62(12):830-5. Pubmed PMID: 16299090.

[4]. Namrata M, Ganapathy D. Light cure devices. International Journal of Orofacial Research. 2017 Jul 1;2(2):37.

[5]. Forst L, Noth IM, Lacey S, Bauer S, Skinner S, Petrea R, Zanoni J. Barriers and benefits of protective eyewear use by Latino farm workers. J Agromedicine. 2006;11(2):11-7. Pubmed PMID: 17135138.

[6]. Lipscomb HJ. Effectiveness of interventions to prevent work-related eye injuries. Am J Prev Med. 2000 May;18(4 Suppl):27-32. Pubmed PMID: 10793278.

[7]. Dingsdag, D., Winder, C., Dain, S. Barriers to compliance with eye protection programs in the NSW coal mining industry. Productivity, ergonomics and safety - the total package conference.1998.

[8]. Forrest KY, Cali JM, Cavill WJ. Use of protective eyewear in U.S. adults: results from the 2002 national health interview survey. Ophthalmic Epidemiol. 2008 Jan-Feb;15(1):37-41. Pubmed PMID: 18300087.

[9]. Shaw WS, Robertson MM, McLellan RK, Verma S, Pransky G. A controlled case study of supervisor training to optimize response to injury in the food processing industry. Work. 2006;26(2):107-14. Pubmed PMID: 16477102.

[10]. Vink P, Koningsveld EA, Molenbroek JF. Positive outcomes of participatory ergonomics in terms of greater comfort and higher productivity. ApplErgon. 2006 Jul;37(4):537-46. Pubmed PMID: 16759626.

[11]. Salazar MK, Takaro TK, Connon C, Ertell K, Pappas G, Barnhart S. A description of factors affecting hazardous waste workers' use of respiratory protective equipment. ApplOccup Environ Hyg. 1999 Jul;14(7):470-8. Pubmed PMID: 10461403.

[12]. Simpson EM, Moll EK, Kassam-Adams N, Miller GJ, Winston FK. Barriers to booster seat use and strategies to increase their use. Pediatrics. 2002 Oct;110(4):729-36. Pubmed PMID: 12359786. 